\title{
Meio ambiente e desenvolvimento: uma perspectiva de valoração ambiental de resíduos sólidos em uma iniciativa de economia solidária
}

\author{
Vinicius de Camargo Machado ${ }^{1}$ \\ Silvio Cesar Arend ${ }^{2}$
}

\begin{abstract}
Resumo
A preocupação com o meio ambiente toma proporções em nível mundial, uma vez que embora haja consenso de que é preciso existir ações coletivas de maior prudência na utilização dos recursos naturais, tanto no presente como para as gerações futuras, não há uma percepção de comportamento que sustente essa necessidade, pelo menos de forma empírica. Dessa forma o objetivo desse estudo tratou de estabelecer a relação entre a teoria de alguns métodos e técnicas de valoração ambiental. $\mathrm{O}$ artigo está organizado em seis subseções: aspectos teóricos do desenvolvimento sustentável; valoração ambiental perspectiva metodológica; método de valoração econômica e ambiental; o case e as considerações finais. Utilizou-se de um caso real a fim de verificar a conexão entre a teoria e a prática, sendo oportuno destacar que ao final do estudo foi possível apontar algumas considerações conclusivas tais como a inviabilidade da implantação de aterro sanitário para um contexto de um Município com capacidade geradora de resíduos sólidos de pouco mais de 52 toneladas/dia. Iniciativa de inclusão social e potencializadora de trabalho e renda, via inclusão de indivíduos vulneráveis, mesmo em pequena escala, mostrou-se significativa, econômica e financeiramente, quando comparada à alternativa de implantação de aterros, com resultados substanciais tanto monetariamente como em relação ao volume de resíduos sólidos retirados do meio ambiente: 175 toneladas em 17 meses de projeto, com baixo investimento pela Prefeitura Municipal que financia o projeto gerenciado pela instituição proponente. A projeção dos resíduos sólidos retirados chega à estimativa de 2,4 milhões de toneladas em 20 anos.
\end{abstract}

Palavras-Chave: Meio ambiente. Valoração econômica. Desenvolvimento. Alternativa.

\section{Environment and development: a perspective of environmental valuation of solid waste in a solidarity economy initiative}

\begin{abstract}
The concern with the environment takes on proportions worldwide, since although there is a consensus that it is necessary to have collective actions of greater prudence in the use of natural resources, both in the present and for future generations, there is no perception of behavior that sustain this need, at least empirically. Thus, the objective of this study tried to establish the relationship between the theory of some methods and techniques of environmental valuation. The article is organized into six subsections: theoretical aspects of sustainable development; environmental valuation methodological perspective; economic and environmental valuation method; the case and the final considerations. We used a real case in order to verify the connection between theory and practice, and it is worth noting that at the end of the study it was possible to point out some conclusive considerations such as the infeasibility of the landfill implantation for a context of a Municipality with generating capacity for solid waste of just over 52 tons / day. Initiative for social inclusion and potentializing work and income, via the inclusion of vulnerable individuals, even on a small scale, proved to be significant, economically and financially, when compared to the alternative of landfill implantation, with substantial results both in terms of money and volume. of solid waste removed from the environment: 175 tons in 17 months of the project, with a low investment by the City Hall that finances the project managed by the proposing institution. The projected solid waste removed reaches an estimated 2.4 million tonnes in 20 years.
\end{abstract}

Keywords: Environment. Economic Valuation. Development. Alternative.

${ }^{1}$ Doutorando do Programa de Pós-Graduação em Desenvolvimento Regional da Universidade de Santa Cruz do Sul (UNISC). https://orcid.org/0000-0002-3223-6363 E-mail: viniciusdecamargomachado@gmail.com

\footnotetext{
2 Doutorado em Economia (UFRGS). Professor do Programa de Pós-Graduação em Desenvolvimento Regional (PPGDR) da Universidade de Santa Cruz do Sul (UNISC). https://orcid.org/0000-0001-7685-3710

E-mail: silvio@unisc.br
} 


\section{Introdução}

Nos últimos anos, com o advento do desenvolvimento tecnológico, é inegável que a humanidade foi transformando os seus hábitos de consumo e por conseguinte a sua capacidade de gerar externalidades foram potencializadas a ponto de sinalizar para um esgotamento dos recursos naturais para as gerações futuras. Embora o homem possua características primitivas de ser uma espécie que se auto adapta aos diferentes ambientes - o modus de vida no deserto, no frio do continente antártico, na diversidade da floresta da Amazônia - o que demostra que essa possibilidade surge à medida que há modificação desses espaços habitados, pois as condições naturais são modificadas pelo homem para suportá-lo enquanto habitante.

No entanto, esse processo parece ser uma condicionante natural que remete à préhistória, pois sempre houve uma alteração nas condições naturais pela ação do homem a fim de atender suas necessidades, o meio ambiente sempre foi modificado para a subsistência humana. Conforme Dias (2011, p. 1) “a construção pelos seres humanos de um espaço próprio de vivência, diferente do natural, se deu sempre à revelia e com a modificação do ambiente natural". O autor afirma ainda que o homem em função da sua sobrevivência, de um modo ou de outro, sempre modificou o ambiente natural.

Naquela época a capacidade humana de interferência não se fazia sentir em uma escala que pudesse afetar decisivamente a natureza, apesar de haver registros de que episódios isolados ocorreram, relacionados à caça de grandes animais. Fato é que à medida que o homem se organiza em grupo e desenvolve instrumentos que potencializam seu modo de vida os efeitos da sua intervenção na natureza começam a ser ampliados.

Entretanto, a capacidade humana de planejar as atividades difere-se dos demais animais, pois ao passo que o homem pensa previamente o que fazer, os outros seguem seu instinto, ou seja, a intervenção do ser humano é pensada, é trabalhada e dos animais é instintiva, mas ambos acabam alterando o seu meio. Parece que essa forma pensada de exercer o trabalho culmina com um dos grandes paradigmas no decorrer da evolução humana em relação ao meio ambiente.

Ao realizar a analogia entre a forma de evolução ou construção entre o fazer do homem e do animal Dias retrata com propriedade o dilema que a humanidade se encontra após os milhares de anos percorridos.

O homem passou a fazer o que todos os outros animais faziam, só que melhor. Construiu represas maiores e melhores do que aquelas que constroem os castores, desenvolveu a capacidade de tecer fibras vegetais melhor do que os animais, construiu 
abrigos melhor do que as outras espécies conseguiam, aperfeiçoou seus métodos de caça e pesca, tornando-se o predador mais temido, superando os animais mais ferozes que existiam. Deste modo, a capacidade de intervenção humana sobre o meio ambiente ao longo dos anos foi sendo multiplicada de uma forma jamais imaginada pelo próprio homem, superando todos os limites (DIAS, 2011, p. 3, grifo nosso).

Justamente nesse contexto de superação dos limites de intervenções provenientes da ação do homem no meio ambiente é que surge a necessidade de encontrar métricas que possam vir não somente a valorar esse processo predatório, como também valorizar, dar importância à necessidade do cuidado ambiental, criando condições mínimas para que os indivíduos estabeleçam nexo para com o status atual.

O que demonstra ser positivo nesse quadro é a preocupação mundial aparente sobre a temática ambiental, desde meados do início do século XX, pois embora seja um tema espinhoso por estar relacionado a interesses que vão além dos aspectos ambientais e este ter surgido de divergências ambientais e acidentes, o ideário do desenvolvimento sustentável se fez presente e em poucos anos acabou ganhando não somente solidez científica, mas política.

\section{A perspectiva teórica do desenvolvimento sustentável}

A definição de qualquer conceito já é uma condição extremamente delicada, por ser auto definidor e pela condição da imutabilidade na sua grande maioria. É diferente o que ocorre com o Desenvolvimento Sustentável, não segue essa lógica, muito em função de tratar-se de um entendimento em construção, podendo ser interpretado como positivo ou como uma fraqueza. Conforme BURSZTYN e BURSZTYN (2012) “o conceito de Desenvolvimento Sustentável ainda está à mercê de ambiguidades e incertezas. Mas é um vetor importante para se entender e enfrentar os problemas atuais da humanidade."

Essa busca resolutiva desses problemas com base nesse conceito tem a relevância de aproximar a visão econômica e por vezes sociais ao meio ambiente, o que reveste de significância e qualidade a discussão agora transdisciplinar. É oportuno mencionar que a formatação desse debate ocorre em um cenário em que estavam ocorrendo importantes transformações, o que BURSZTYN e BURSZTYN (2012) descrevem como “[...] a crise das utopias do século vinte (socialismo, salvacionismo científico, welfare state, consumismo, desenvolvimentismo), o mundo não encontrou a paz nem resolveu as necessidades básicas, a ciência não solucionou todos os problemas (e até criou outros), o mundo natural se degradou [...]." 
O conceito de forma mais elaborada surge no início da década de 1970, em momento de discussão do crescimento econômico e a relação com o meio ambiente, o que foi reforçado pelo relatório do Clube de Roma, que tinha na sua essência a ideia de crescimento zero, a fim de evitar a catástrofe ambiental. Mas acima de tudo tinha uma proposição conciliadora, pois ao mesmo tempo em que reconhece a importância do progresso técnico aborda os limites ambientais e a condição de que o crescimento econômico é condição necessária, mas não suficiente para a eliminação da pobreza e disparidades sociais (ROMEIRO, 2003, p. 6).

Como mencionado acima, o conceito está em construção, sendo assim existem divergências de forma geral que podem ser organizadas em duas partes ou visões. A primeira representa a visão dominante, denominada de Economia Ambiental, tem por entendimento que os recursos naturais não têm limite para serem utilizados na expansão econômica. A segunda visão está associada à chamada Economia Ecológica, diferentemente da anterior, entende os recursos ambientais como sendo finitos e, portanto, precisam ser harmonizados.

\section{A valoração ambiental}

A tarefa de estimar algum valor monetário, independente do que esteja procurando mensurar, já é uma tarefa nada fácil e, quando se trata de recursos ambientais, o grau de complexidade e subjetividade tornam a tarefa muito mais penosa e incerta. A valoração pode facilitar a percepção comparativa que os indivíduos acabam estabelecendo no seu cotidiano e o mais importante é o efeito que pode gerar, pois, segundo Ortiz (2003, p.81):

\footnotetext{
"existe uma dependência de um sistema maior, o que chama de ecossistema dos recursos naturais, inclusive que podem vir a comprometer a perpetuidade das espécies animais e vegetais, e devido a essa importância a associação de valor a bens ou recursos ambientais, faz todo o sentido, embora também mencione o aspecto ético e moral."
}

Embora existam vários métodos que procuram mensurar os valores intrínsecos dos recursos naturais evitando a quantificação econômica, é oportuno destacar que o valor relevante de um recurso ambiental é aquele que efetivamente irá importar para a tomada de decisão, que estabelecerá uma relação benéfica para o bem-estar da coletividade. Partindo desse pressuposto a tentativa de criar essa condição de análise parece ficar condicionada à comparação ou ao que é chamado no jargão econômico de trade-off - escolha, no caso a melhor, ou a mais racional. Segundo Ortiz (2003, p.81), 
“[...] a valoração econômica ambiental busca avaliar o valor econômico de um recurso ambiental através da determinação do que é equivalente, em termos de outros recursos disponíveis na economia, que estaríamos (os seres humanos) dispostos a abrir mão de maneira a obter uma melhoria de qualidade ou quantidade do recurso ambiental [...]."

A valoração econômica ambiental não tem o intuito de simplesmente estabelecer um valor no sentido de precificação dos recursos naturais ou ao próprio contexto amplo, o meio ambiente, mas sim valorar os serviços ou recursos que emergem da melhor escolha, pois este está associado ou representa a melhor opção, quantitativamente ou qualitativamente de bemestar. A essa resultante pode ser atribuída a disposição que os indivíduos estariam dispostos a dispender monetariamente uma determinada quantia a fim de obter melhor benefício ambiental, raciocínio esse que vale para a condição inversa, ou seja, uma disposição a aceitar um decréscimo ou piora na oferta de um recurso ambiental.

A ideia central da valoração econômica é proporcionar uma métrica que tenha condições de representar os benefícios sociais ou custos advindos das escolhas realizadas na ocasião da comparação entre os recursos ambientais ou serviços escassos. Estabelecer essa métrica a partir de valores monetários possibilita a comparação com valores de mercado, o que permite ou abreviar a tomada de decisão.

Mas como já foi mencionado no começo dessa seção, e agora ratificado, a tarefa de realizar essa mensuração não é nada fácil, por não ser um processo corriqueiro, pela complexidade e subjetividade envolvida, a dependência de dados críveis e a escolha do melhor método torna essa estimativa hercúlea para quem a propõe.

\section{Perspectiva metodológica}

Pela perspectiva da Economia Ambiental, o primeiro método é o do Valor Econômico Total (VET) de um recurso natural: o objetivo desse método é somar valor de uso e do valor de não uso de um recurso ambiental, sendo que o valor de uso subentende a soma dos valores de uso direto e indireto e o valor de opção futura de uso deste recurso. Por valor de uso direto entende-se como o valor propriamente derivado da utilização ou consumo direto do recurso. No caso do valor de uso indireto é derivado do uso do recurso em outra lugar de conservação do recurso originalmente utilizado. O valor de opção está relacionado à quantidade que os indivíduos estariam dispostos a despender para manter o recurso ambiental para o futuro. 0 
valor de não uso é o valor relacionado à não utilização do recurso ambiental, está relacionado à satisfação percebida do individuo de que o respectivo recurso está intacto.

Segundo Ortiz (2003, p.83),

"[...] o valor econômico total de um recurso ambiental é a soma de todos os valores de uso direto e indireto (que podem ser vários) mais o seu valor de opção e o seu valor de existência. Entretanto, deve se tomar o cuidado de não adicionar valores mais de uma vez, ou, ainda, não somar valores que não seriam possíveis se outro uso do recurso tiver sido considerado na valoração econômica [...]."

Na sequência é necessária a abordagem do tempo, variável fundamental para a construção de decisões que envolvem a valoração, como, por exemplo, a análise da relação custo/benefício de uma preferência qualquer, que deve considerar o momento atual e os benefícios do presente comparando com os do futuro. O que é válido para os custos incorridos no tempo presente e futuro, que consolidados devem indicar a decisão a ser tomada, trata-se do que os economistas chamam de decisão racional. A problemática que estabelece essa análise é acerca de qual seja a taxa de desconto ideal para ser considerada, pois esta irá refletir ou estimar a capacidade presente e/ou futura. Conforme Ortiz (2003, p.84), pode ser constatado que a taxa e o tempo são variáveis imperativas para a mensuração de valoração ambiental, " [...] ao utilizar uma taxa de desconto elevada (baixa), o economista está determinando que as gerações futuras darão muito (pouca) importância ao recurso analisado [...]".

Para finalizar, é oportuno destacar a limitação que o autor salienta em relação à agregação temporal de custos e benefícios, pois considera ser mais pertinente a utilização em uma análise de curto prazo, pois as variáveis de incertezas relacionadas ao futuro são menores, o que não ocorreria no longo prazo, podendo induzir a conclusões equivocadas.

\section{Métodos de valoração econômica ambiental}

Existem vários autores trabalhando na consolidação de métodos que possam melhor representar a valoração de um recurso ambiental, mas de forma geral a literatura especializada classifica-os como direto e indireto, observados ou hipotéticos e, ainda, baseados em função de produção ou função de demanda. A proposição nesta seção é realizar um breve resgate de alguns desses métodos. 


\subsection{Método indireto}

Consiste na valoração econômica de um recurso ambiental a partir de observação dos indivíduos em mercados que atuem com ativo ambiental, podendo ser bens complementares ao consumo do bem ambiental ou ainda bens substitutos. Um desses métodos é o custo de viagem, tem sua origem atribuída ao economista Harold Hoteling em 1949. A ideia consiste em estimar o valor de uso recreativo através dos gastos ocorridos na visita de algum lugar, ou seja, o que foi despendido no percurso da visita, tais como gastos associados à viagem. A resultante dessa mensuração indicara o valor de uso do lugar visitado.

O método de preços hedônicos objetiva estimar um preço implícito por atributos ambientais de bens transacionados em mercado. Os mercados principais desse método são o imobiliário e o de trabalho, nos quais o valor do bem é a variável dependente e as demais variáveis, ou seja, as características atribuíveis a este bem, são as variáveis explicativas, que determinam este preço e, entre estas, incluem-se as ambientais.

É oportuno destacar que a subjetividade desse método já parte desde seu nome, mas a sua essência consiste em atribuir a hipótese de que os indivíduos irão perceber as mudanças na quantidade ou qualidade de benefícios ambientais e que o mercado analisado é competitivo e as informações são todas disponíveis.

\subsection{Método direto}

Nessa abordagem o método de valoração direta estabelece a consulta diretamente ao indivíduo na busca de respostas das suas preferências individuais por bens ou serviços ambientais. O método de valoração contingente é um dos principais dessa subdivisão, consiste em pesquisa amostral que tenta identificar de maneira monetária as preferências individuais para bens não transacionados no mercado. Trabalha-se com hipóteses criadas via cenários, nos quais se estabelecem possíveis comportamentos.

O outro método é o ranqueamento contingente, nesse método os indivíduos recebem vários cartões com informações hipotéticas e respostas relativas à situação ambiental, como por exemplo nível de congestionamento, taxa de administração de um parque etc. Dessa forma são convidados a responder a esses problemas organizando esses cartões segundo suas preferências 
e os valores relativos aos recursos podem ser inferidos e ranqueados, utilizando-se as taxas marginais de substituição.

\section{Um exercício de valoração econômica ambiental}

Após as considerações acerca da valoração econômica ambiental, esta seção tentar esboçar a estimativa de valoração de resíduos sólidos coletas por indivíduos que se encontram em situação de risco, sob a fronteira da miséria, um case real.

Esses indivíduos fazem parte de um dos projetos de extensão da Universidade de Cruz Alta - UNICRUZ - em parceria com a Prefeitura Municipal de Cruz Alta e o projeto tem por objetivo a coleta seletiva em oito bairros do município. Os indivíduos que são identificados como catadores, estão organizados em quatro associações formais, que totalizam 40 famílias que buscam renda para sua subsistência.

$\mathrm{Na}$ sequência são apresentados dados que retratam as principais variáveis que subsidiaram a análise, destacando os dados do Ministério do Meio Ambiente (MMA), que retratam como a Política Nacional de Resíduos Sólidos (PNRS) em 2015. Embora sejam informações defasadas na perspectiva temporal, não interferem significativamente para o que se propõe esse estudo.

A Tabela 1 traz o tempo em que os resíduos sólidos demoram para se decompor na natureza, são informações que passam despercebidas da população, ainda mais quando relacionadas com a expectativa de vida (72,7 anos para o Brasil, conforme o IBGE, 2019) e da quantidade de utensílios que rodeiam todos os dias o fazer de qualquer individuo independentemente de sua condição social.

Tabela 1 - Tempo de decomposição dos materiais na natureza

\begin{tabular}{lc}
\hline Material & Tempo de decomposição \\
\hline Papel & 3 a 6 meses \\
Metal & Mais de 100 anos \\
Alumínio & Mais de 200 anos \\
Plástico & Mais de 400 anos \\
Vidro & Mais de 1000 anos \\
\hline
\end{tabular}

Fonte: Ministério do Meio Ambiente do Brasil, 2019. Adaptado pelo autor. 
Na Tabela 2 são apresentados os dados que representam como estava a distribuição dos municípios brasileiros em relação à condição de terem aterro sanitário ou lixão e aterro controlado, bem como o percentual de população que está sujeita a uma ou outra condição.

Tabela 2 - Municípios que dispõem seus Resíduos em aterros Sanitários 2015

\begin{tabular}{l|c|c|c}
\hline $\begin{array}{l}\text { Número de } \\
\text { Municípios }\end{array}$ & População em milhões & (\%) total da população & Classificação \\
\hline 2.215 & 129 & $63 \%$ & Aterro Sanitário \\
3.355 & 74,7 & $37 \%$ & Lixão e Aterro controlado \\
\hline
\end{tabular}

Fonte: Ministério do Meio Ambiente do Brasil, 2019. Adaptado pelo autor.

As informações consolidadas na Tabela 3 sintetizam a posição dos municípios brasileiros quanto à existência de planos de gestão integrada de resíduos sólidos. O que merece destaque, infelizmente negativo, é que aproximadamente a metade dos municípios não tem nenhum plano oficial e, se considerar que o fato de que ter formalmente um instrumento norteador, não garante efetividade, podemos imaginar que, não tendo nenhum instrumento nesse sentido, a situação seja mais delicada do ponto de vista ambiental. O percentual de $48 \%$ da população desassistida por um plano corresponde a 97 milhões de pessoas.

Tabela 3 - Municípios que tinham Planos de Gestão Integrada de Resíduos Sólidos em 2015

\begin{tabular}{l|c|c|c}
\hline $\begin{array}{l}\text { Número de } \\
\text { Municípios }\end{array}$ & População em milhões & $(\%)$ total da população & Classificação \\
\hline 2.325 & 107 & $52 \%$ & Com plano \\
3.245 & 97 & $48 \%$ & Sem plano \\
\hline
\end{tabular}

Fonte: Ministério do Meio Ambiente do Brasil, 2019. Adaptado pelo autor.

A Tabela 4 mostra como os municípios brasileiros estão distribuídos em relação à coleta seletiva, ou seja, que possuem essa alternativa que, além de ser uma forma de proporcionar renda às pessoas que se encontram sob a condição de vulnerabilidade social e econômica, o que embora não seja aprofundado nesse estudo, empiricamente é possível que seja uma das principais estratégias de solução para os dois problemas, ou seja, inserção social e resíduos sólidos. Um dado que é destacado pelo MMA, em relação ao percentual dos resíduos coletados nesses municípios que possuem coleta seletiva, apenas $2 \%$ são, de fato, separados para reciclagem. 
Tabela 4 - Municípios que possuem coleta seletiva 2014

\begin{tabular}{l|c|c}
\hline Número de Municípios & (\%) total da população & Classificação \\
\hline 1.320 & $23,70 \%$ & Com coleta seletiva \\
2.445 & $43,90 \%$ & Sem coleta seletiva \\
1.805 & $32,40 \%$ & Sem informação \\
\hline
\end{tabular}

Fonte: Ministério do Meio Ambiente do Brasil, 2019. Adaptado pelo autor.

O Quadro 1 traz informações sobre estimativas de quilogramas de resíduos sólidos gerados por pessoa em média durante um dia. Apresenta também o número expressivo de catadores e um conjunto de instituições espalhadas nos municípios do Brasil que estão relacionados à coleta seletiva. $\mathrm{O}$ que chama a atenção é o fato de embora existir significativo número de catadores, o total de trabalhadores informados pelo MMA que atuam ou que estão em seus registos, soma apenas pouco mais de 30 mil trabalhadores. Destaca-se que conforme consta no sítio do MMA, essas informações também serviram para o levantamento do sistema nacional sobre saneamento em 2014.

Quadro 1 - Indicadores sobre Resíduos sólidos 2013 - 2014

\begin{tabular}{|l|l|}
\hline Variáveis & \multicolumn{1}{c|}{ Resultantes } \\
\hline Uma pessoa produz/dia em média & $1,04 \mathrm{~kg}$ de resíduos \\
\hline 600 mil catadores & $\begin{array}{l}1.175 \text { cooperativas ou associações de catadores, } \\
\text { distribuídas em } 684 \text { municípios. }\end{array}$ \\
\hline Total: 30.390 trabalhadores
\end{tabular}

Fonte: Ministério do Meio Ambiente do Brasil, 2019. Adaptado pelo autor.

O Quadro 2 apresenta a proporção de desembolso de um investimento para a instalação de um aterro sanitário. Esse critério dá a noção do custo por fase do investimento, ou seja, da implantação, operação e manutenção e encerramento, pois estabelece um horizonte de vinte anos. São critérios que ajudarão a melhor dimensionar o aporte de recursos necessários em empreendimentos públicos como este, servindo de base comparativa.

Quadro 2 - Custo da instalação de aterros sanitários - Critério

\begin{tabular}{|l|l|}
\hline Itens & \multicolumn{1}{c|}{ Critério } \\
\hline Custo da implantação & $5 \%$ do total de investimento do aterro \\
\hline Custo de operação e manutenção & $85 \%$ do total de investimento no aterro \\
\hline Custo de encerramento e pós-encerramento & $10 \%$ do total de investimentos no aterro \\
\hline Vida útil & 20 anos \\
\hline
\end{tabular}

Fonte: ABETRE/FGV 2007. Adaptado pelo autor. 
Na Tabela 5 é apresentada uma estimativa para um investimento da implantação de um aterro com capacidade de atender uma demanda potencial de recebimento de resíduos sólidos que varia de 100 toneladas/dia a 2.000 toneladas/dia. O valor base foi corrigido pelo Índice Nacional de Construção Civil (INCC - FGV) para o período de 06/2014 até o mês de 04/2019, que apurado correspondeu a uma variação percentual da ordem de $21,42 \%$. Merece destaque os recursos necessários para investimentos dessa natureza, pois das três capacidades apresentadas a ordem de desembolso varia entre $\mathrm{R} \$ 63,6$ milhões a $\mathrm{R} \$ 638,4$ milhões.

Tabela 5 - Valor estimado para implantação de um aterro em $\mathrm{R} \$$ milhões

\begin{tabular}{l|c|c|c}
\hline Aterro & Capacidade (t/dia) & Vlr. Base (06/2014) & Vlr. Atualizado (04/2019) \\
\hline Pequeno porte & 100 & 52,4 & 63,6 \\
Médio porte & 800 & 236,5 & 287,2 \\
Grande porte & 2.000 & 525,8 & 638,4 \\
\hline
\end{tabular}

Fonte: ABETRE/FGV, 2007. Adaptado pelo autor.

Seguindo a análise, a Tabela 6 apresenta os bairros do município de Cruz Alta que possuem coleta seletiva, que servirão de objeto do estudo para o estabelecimento de valoração dos resíduos sólidos gerados nestes oito bairros. É possível constatar que eles têm uma abrangência significativa do total da população do Município de Cruz Alta-RS que tem 60.693 habitantes (IBGE, 2019), atingem 11.429 habitantes, o que significa aproximadamente 19\% do total da população. Em relação à coluna potencial gerador de resíduos, a estimativa realizada toma como parâmetro a variável do Quadro 1 que estima que cada pessoa em média produz 1,04 $\mathrm{kg} /$ dia de resíduos sólidos. Dessa forma o potencial mensurado resulta em aproximadamente 12 toneladas/dia.

Tabela 6 - Bairros de Cruz Alta - RS que possuem coleta seletiva 2019

\begin{tabular}{l|r|c}
\hline Bairros & População & Potencial gerador de resíduos (t/dia) \\
\hline Ferroviário (Dirceu) & 1.288 & 1,34 \\
Bonini II & 1.315 & 1,37 \\
Bonino I & 1.013 & 1,05 \\
Vila Hilda & 1.169 & 1,22 \\
Jardim América & 766 & 0,80 \\
Centro & 4.988 & 5,19 \\
Bairro Central & 317 & 0,33 \\
Bairro Conceição & 573 & 0,60 \\
\hline Total & 11.429 & 11,89 \\
\hline
\end{tabular}

Fonte: Brasil Sabido, 2019. Adaptado pelo autor. 
Na Tabela 7 os dados relacionados foram coletados diretamente com a coordenação do projeto. Destaca-se o elevado volume de resíduos sólidos retirados do meio ambiente ao longo de dezessete meses, perfazendo montante de mais de $175 t$ além de renda direta a essas famílias envolvidas. Destaca-se que esses materiais compreendem o peso de papel, plástico e metal; não há registro deles de forma separada, pois são pesados em conjunto. O valor comercializado corresponde ao montante destinado aos indivíduos envolvidos no projeto na ocasião da comercialização.

Tabela 7 - Histórico da coleta seletiva do Projeto 2019

\begin{tabular}{l|c|c}
\hline Mês/ano & Quantidade kg/mês & Vlr.total comercializado R\$1,10/kg \\
\hline Dez/17 & 7.056 & $7.761,16$ \\
Jan/18 & 6.455 & $7.100,28$ \\
Fev/10 & 7.399 & $8.138,46$ \\
Mar/18 & 4.469 & $4.915,68$ \\
Abr/18 & 4.442 & $4.886,31$ \\
Mai/18 & 11.840 & $13.024,22$ \\
Jun/18 & 9.539 & $10.493,01$ \\
Jul/18 & 10.981 & $12.079,54$ \\
Ago/18 & 15.946 & $17.540,82$ \\
Set/18 & 11.709 & $12.880,03$ \\
Out/18 & 13.166 & $14.482,60$ \\
Nov/18 & 10.376 & $11.413,60$ \\
Dez/18 & 13.752 & $15.126,98$ \\
Jan/19 & 8.973 & $9.870,30$ \\
Fev/19 & 10.975 & $12.072,28$ \\
Mar/19 & 15.036 & $16.539,31$ \\
Abr/19 & 13.220 & $14.542,00$ \\
\hline Total & 175.333 & $192.866,59$
\end{tabular}

Fonte: Dados da pesquisa.

A Tabela 8 é uma estimativa da valoração dos resíduos sólidos coletados pelo projeto, as variáveis críticas usadas para essa mensuração foram originárias das informações da Tabela 7, ou seja, a partir da média dos dezessete meses de coleta, apurou-se o valor presente, o que resultou o montante de $\mathrm{R} \$ 136.141,08$ ao ano. A taxa de juros considerada para atualizar os respectivos fluxos futuros foi a taxa Selic (Sistema Especial de Liquidação e de Custódia) de 6,5\% ao ano, data base do mês de junho de 2019. Outro aspecto diz respeito à posição conservadora com que foi mensurado esse resultado, pois não se projetou variação no valor do quilograma comercializado, apenas corrigiu-se o fluxo relevante através de planilhas eletrônicas de Excel. O resultado ao longo de vinte anos foi de R\$ 5,7 milhões, o que dá uma noção do valor de mercado dos resíduos 
sólidos retirados do meio ambiente, mas sobretudo o que parece mais relevante é o volume estimado de resíduos nesse mesmo período, 2,4 milhões de toneladas.

Tabela 8 - Estimativa de valor futuro da coleta seletiva do Projeto 2039

\begin{tabular}{l|c|c}
\hline Variáveis Críticas & Valores & Resultado \\
\hline Valor Presente (VP) & R\$ 136.141,08 & --- \\
Taxa (Selic) & $6,5 \%$ a.a. & --- \\
Tempo (anos) & 20 & --- \\
Valor Futuro (VF) & --- & $\mathrm{R} \$ 5.765 .432,30$ \\
Coleta Seletiva & --- & 2,4 milhões de toneladas \\
\hline
\end{tabular}

Fonte: Dados da pesquisa.

Na Tabela 9 encontram-se consolidados alguns dados que já figuraram no decorrer do estudo. Em termos de recursos financeiros para aportar em investimento de implantação de aterros fica muito claro o substancial volume de recursos necessários, mas o outro fato relevante que a pesquisa traz diz respeito à necessidade total do Município, considerando a sua capacidade potencial de 51,2 toneladas/dia, o que praticamente representa $50 \%$ da capacidade do menor aterro. Em relação ao projeto a coleta tem um custo para a Prefeitura municipal de pouco mais de R\$317 mil, ao longo dos dezessete meses aqui consolidados. Sobre o território do projeto, ou seja, os bairros, há um potencial gerador a ser explorado da ordem de 11,5 toneladas/dia, o que corresponde a uma renda potencial de um pouco mais de $\mathrm{R} \$ 12$ mil por dia. Em termos de potencial do restante do Município o potencial é da ordem de 51,2 toneladas/dia

Tabela 9 - Valor estimado para implantação de um aterro versos o projeto

\begin{tabular}{l|c|c}
\hline Aterros & Capacidade (t/dia) & Vlr. em R\$ milhões \\
\hline Pequeno porte & 100 & 63,6 \\
Médio porte & 800 & 287,2 \\
Grande porte & 2.000 & 638,4 \\
\hline Projeto & Capacidade (t/dia) & Vlr. em (R\$) mil \\
Coleta Seletiva & 0,344 & $317.233,09(17$ meses) \\
Potencial Gerador & 11,5 & $12.650,00$ (dia) \\
\hline Município & Capacidade (t/dia) & Vlr. em (R\$) mil \\
Potencial Cruz Alta & 51,2 & $56.320,00$ (dia) \\
\hline
\end{tabular}

Fonte: Dados da pesquisa.

\section{Considerações Finais}

Podemos considerar que há várias alternativas de valoração ou métodos para tal que podem subsidiar a mensuração e fundamentar não somente uma correta avaliação em termos 
de recursos naturais extraídos ou os próprios resíduos que foram em algum momento descartados no meio ambiente, mas sinalizar como ferramenta crível a ser usada na ocasião da criação de políticas públicas que tenham a preocupação com o meio ambiente.

Antes de seguir destacando outras considerações que se fazem necessárias, utiliza-se mais uma vez de Ortiz (2003, p.97) para sintetizar a realidade que se espera que esse trabalho possa futuramente ser parte da mudança: "[...] no Brasil, ainda são poucas as experiências com a utilização de métodos de valoração econômica ambiental para apoiar a formulação de políticas, quando comparada com os casos norte americanos e europeus [...]".

Embora o estudo não traga informações da capacidade de investimento da Prefeitura Municipal de Cruz Alta, a observação dos dados projetados para o aporte de investimento em aterros sanitários como alternativa para a problemática dos resíduos sólidos aparenta não ser econômica e financeiramente suportável, visto que considerando apenas o investimento em um aterro de pequena capacidade, ou seja de 100 toneladas/dia, o desembolso gira em torno de R\$ 63,6 milhões e ainda quando cruzado com a informação de geração potencial de resíduos sólidos do Município de maneira a desconsiderar o que já é destinado via projeto, não demostra ser novamente a alternativa a ser considerada, pois este potencial de geração de resíduos sólidos gira em torno de 51,2 toneladas/dia, indicando uma subutilização caso fosse essa a decisão de escolha.

Outra importante aspecto é a renda que é gerada a partir da comercialização dos resíduos sólidos coletados, que ao serem dimensionados ao longo do tempo, vinte anos, mesmo tempo dos investimentos alternativos (implantação dos aterros), mostrou um substancial montante, tratando-se de indivíduos que estão na linha da pobreza extrema, projeção essa realizada de modo bastante conservadora, pois não levou em conta possível aumento no valor da comercialização. Esse projeto em termos de desembolso para a prefeitura resultou em um montante de pouco mais de $\mathrm{R} \$ 317$ mil, que novamente, quando comparado com as demais alternativas objeto desse estudo, demostra ser de baixo desembolso e grande retorno.

Em termos de volume de resíduos sólidos já retirados do meio ambiente com essa iniciativa de coleta seletiva nesses oito bairros do Município de Cruz Alta que correspondem a aproximadamente $19 \%$ do total da população, o volume de mais de 175 toneladas, de papel, metal e plástico, é algo significativo, pois a decomposição desses resíduos caso permanecessem expostos às condições do meio ambiente levariam aproximadamente 3 a 6 meses no caso do papel, mais de 100 anos o metal e mais de 400 anos o plástico. Projetando esse total de resíduos 
retirado do meio ambiente ao longo de vinte anos, mantidas as condições do projeto em termos de capacidade de coleta, seria possível que essa iniciativa tenha condições de coletar aproximadamente 2,4 milhões de resíduos sólidos, sem mencionar os efeitos benéficos que proporcionariam à coletividade.

\section{Referências}

ASSOCIAÇÃO BRASILEIRA DE EMPRESAS DE TRATAMENTO DE RESÍDUOS. Estudo sobre os Aspectos Econômicos e Financeiros da implantação e Operação de Aterros Sanitários elaborado pela Fundação Getúlio Vargas. 2007. Disponível em:

<http://www.abetre.org.br/estudos-e-publicacoes/publicacoes-2>. Acesso em: 25 maio. 2019.

BANCO CENTRAL DO BRASIL. Taxa Selic. Disponível em: <

https://www.bcb.gov.br/controleinflacao/taxaselic >. Acesso em: 25 maio. 2019.

BRASIL SABIDO. População das cidades brasileiras. Disponível em:

<http://brasilsabido.com.br/populacao/cruz-alta-rs-125.html>. Acesso em 25 maio.2019.

BURSZTYN, Marcel. BURSZTYN, Maria A. Fundamentos de política e gestão ambiental: os caminhos do desenvolvimento sustentável. Ed. Rio de Janeiro: Garamond, 2012.

DIAS, Reinaldo. Gestão ambiental: responsabilidade social e sustentabilidade. 2. Ed. São Paulo: Atlas, 2011.

FUNDAÇÃO GETÚLIO VARGAS. Índice de Custo da Construção. Disponível em: < https://portalibre.fgv.br/revista-conjuntura-economica/estatisticas-e-indices/ >.Acesso em: 25 maio. 2019.

INSTITUTO BRASILEIRO DE GEOGRAFIA E ESTATÍSTIVA. Censo demográfico 2010. Disponível em: <https://www.ibge.gov.br/cidades-e-estados/rs/cruz-alta.html>. Acesso em: 25 maio 2019.

MINISTÉRIO DO MEIO AMBIENTE. Impacto das embalagens no meio ambiente. Disponível em : <http://www.mma.gov.br/responsabilidade-socioambiental/producao-e-consumosustentavel/consumo-consciente-de-embalagem/impacto-das-embalagens-no-meioambiente.html >. Acesso em: 25 maio. 2019.

MOTA, José Aroudo; BURSZTYN, Marcel; CÂNDIDO Jr., José e ORTIZ, Ramon. A valoração da biodiversidade: conceitos e concepções metodológicas. In: MAY, P. Economia do Meio Ambiente: teoria e prática. 2으. Ed. SP: Campus/Elsevier, cap. 12, p. 265 - 287, 2010.

ORTIZ, Ramon Arigoni. Economia ou Economia Política da Sustentabilidade. In: MAY, P.H; LUSTOSA, M.C; VINHA, V.D. Economia do Meio Ambiente: teoria e prática. Ed. Rio de Janeiro: Elsevier, 2003. Cap.3, p.81-100.

PORTAL BRASIL. Índice Nacional de Custo da Construção do Mercado. Disponível em: <http://portalbrasil.net/incc.htm>. Acesso em: 25 maio. 2019.

ROMEIRO, Ademar Ribeiro. Economia ou Economia Política da Sustentabilidade. In: MAY, P.H; LUSTOSA, M.C; VINHA, V.D. Economia do Meio Ambiente: teoria e prática. Ed. Rio de Janeiro: Elsevier, 2003. Cap.1, p.1-30. 